\title{
Contracts in Underdeveloped Countries
}

\author{
Brian Harris, Consultant Psychiatrist, Sully Hospital, Cardiff
}

A number of schemes exist to provide aid from the developed countries to those countries which are less privileged and belong to the Third World. For example, the official Guide Book (1978) of the Inter-University Council states: 'The Inter-University Council for Higher Education (IUC) was established in 1946 by the Universities in the United Kingdom, at the request of the British Government, to assist the advancement of higher education in developing countries and, to this end, to encourage co-operation between Universities in those countries and Universities in the United Kingdom ... In 1970 the IUC became a corporate, independent body and entered into a general agreement with the Ministry of Overseas Development which provided that all British official aid to the Universities with which it was associated should as soon as possible be co-ordinated by the Council.'

\section{Contracts}

Contracts of varying length are available. Some contracts are of two to three years and are made with the Govern ments of the underdeveloped countries. The aid is an extremely generous supplement paid by the British Government and in the case of the University of Dar-es Salaam the supplement can amount to five times the salary paid by the Tanzanian Government (BESS, 1980). The aid also extends to every possible facet of individual and family life. On the other hand, there are much shorter-term contracts or lectureships which are financed by the same organization. Apart from accommodation, these short-term visits are also paid for by the British Government. But relatively few psychiatrists take the opportunities provided by either scheme, for a number of possible reasons.

\section{Dificiculties whth longer contracts}

As far as longer-term contracts are concerned, apart from personal and domestic reasons a number of factors have to be considered. Firstly, it has been argued that the structure of the NHS in terms of developing a career does not allow for 'Been to Africa' (Savage, 1979).

It must be admitted that an interviewing committee might well look askance at the curriculum vitae of a candidate who had spent three years in an underdeveloped country unless this was seen as a part of his training. The Handbook for Inceptors and Trainees in Psychiatry (1980) does, in fact, point out the desirability of a period in a developing or underdeveloped country as part of the training of a psychiatrist.

Secondly, there is the problem of 'political situations'. It is true that when political circumstances force doctors on longer term contracts in overseas countries to leave, many of them find it difficult to obtain equivalent positions in the National Health Service. There is no easy answer to this, but one possible solution is for the psychiatrist to remain very much involved with an academic centre in Britain, particularly during the biennial two months home leave.

Thirdly, in terms of psychiatry, the problem of culture comes to the fore, and many are deterred because of crosscultural difficulties. These problems have been reviewed by Leff (1977), and on the whole such difficulties prevent the high standard of academic study which we are used to in the West. However, in countries such as Tanzania, psychiatry is so poorly developed and the standards so basic and elementary that psychiatrists from Britain can easily fit into the existing system and contribute in a constructive way.

\section{Short term viaits}

As far as short term visits are concerned, one of the main reasons for lack of applicants is ignorance of the schemes financed by the IUC. In fact the IUC is very flexible in its attitude to short term visits, as is indicated by the following statement: 'Outward movements may cover visits varying from about two weeks up to four months. Visitors may be members of Council or of its Committees, or senior academic, administrative, library or technician staff of British Universities, or people attached to any other United Kingdom Institutions whose specialism has some bearing on the work of an associated University. The particular purpose of the visits, all of which are in response to an invitation from the overseas University concerned, is virtually unlimited, provided they contribute in some direct or indirect way to the betterment, as an instrument of local development, of the Universities overseas which are associated with the IUC. The visits may be exploratory, for consultation or advice on some aspect of University activity or development, to give lectures or seminars, to serve as external examiners, to organize or take part in training courses, and generally to provide academic enlivenment. They then cover a wide range of University-related topics and purposes.' (IUC, 1978).

The same publication also states: 'The IUC is now associated with some 40 University Institutions in 26 countries, mainly in Africa but also in the Caribbean, in South East Asia, in the Pacific, Mauritius and Malta.'

In case the reference to 'an invitation from the overseas University' should deter anyone, it often only means that the head of department knows of someone in Britain who is willing to 80 and work hard, lending an extra pair of hands to a sometimes desperate situation. Again with reference to Tanzania, on a short-term visit much work can be done with the aid of a translator (usually a medical student). In addition, as in most Third World Countries, there is a fairly large English-speaking population, which includes the educated African Tanzanians, the bi-lingual Asian population (Swahili and English), and other groups such as the 
South African freedom fighters who have taken refuge in Tanzania. A short-term visiting psychiatrist dealing with these groups above takes a considerable work load off the permanent staff. There is also the task of lecturing to the medical students, which takes about a third of the time.

Finally, the exposure to 'African' mental illness, together with the task of fitting it in to the ICD is a valuable training experience. Amazingly, the ICD is regularly used, perhaps because of the prevailing belief that the West has all the answers! It is with difficulty that this belief is dispelled, but it is possible, if the visiting doctor has the necessary humility, and accepts that the visit is a learning experience.
REFERENCES

INTER-UNIVERsITY CounCIL (1980) British Expatriates Supplementation Scheme. IUC/601/17/70. London: IUC.

(1978) IUC and Related Services: A Guide. Second Edition. Foreword by Chairman. London: IUC.

LEFF, J. (1977) The cross-cultural study of emotions. Culture, Medicine and Psychiatry, 1, 317-50.

Royal College of Psychiatrists (1980) Careers in psychiatry, p. 3. In Handbook for Inceptors and Trainees in Psychiatry, eds. T. H. Bewley and S. Mahapatra. Ashford, Kent: Headley Brothers.

Savage, A. (1979) Mission hospital medicine. British Medical Journal, ii, 111-13.

\section{The Work of the Uffculme Clinic}

\section{John A. Harrington, Consultant Psychiatrist and Medical Director, Uffculme Clinic}

The Uffculme Clinic opened 25 years ago as an early psychiatric treatment and research centre and has for the past 15 years functioned as a regional centre for psychotherapy in the West Midlands. Day and in-patients participate in a psychotherapeutic regime which includes a daily analytic psychotherapy group, relaxation therapy, projective art, psychodrama and more traditional occupational and recreational therapies. A weekly community meeting has recently been extended to give staff and patients a large group experience. Patients in intensive treatment are severely affected by neurotic or personality difficulties and are only admitted if they are incapable of functioning at work or at home.

At present there are over 20 out-patient evening or afternoon groups. Individual psychotherapy is offered to a small number of patients for whom group therapy seems inappropriate. There is a social club and a social skills group. Where behavioural therapy seems appropriate, patients are usually referred to the psychology department of their district psychiatric hospital.

\section{Registrar training}

Registrars undergo a year's intensive training in psychotherapy as part of a three and a half year rotational training scheme. Trainees can also attend a day release three-year MRCPsych course under the auspices of the University of Birmingham.

The registrar acts as therapist to an intensive group, supported by a nurse therapist. Each trainee is also therapist to an out-patient group and undertakes individual psychotherapy with a small number of specially selected outpatients. He also sees new out-patients for assessment and participates in brief and supportive psychotherapies and conjoint marital work. Each trainee has a weekly session with a consultant superviser, and there is also weekly group supervision with a consultant psychotherapist. Trainees all participate in a conference when all newly admitted patients are seen. Other training activities include a journal club and weekly staff meetings.

The rotation to Uffculme is best carried out in the last year of a registrar's rotation; trainees seem to gain more from psychotherapy if they are familiar with an eclectic approach to psychiatry. Fifteen years ago, when the scheme first started, Uffculme was not always popular; some trainees saw psychotherapy as alien or irrelevant to the practice of psychiatry. Nowadays most trainees are keen to have psychotherapeutic experience and may continue their links with the Clinic by continuing with their out-patient groups and one or two individual patients.

\section{Higher paychiatric training}

Higher psychiatric training for senior registrars takes the form of either one or two years' full-time experience in Uffculme as part of a rotational scheme, and generally after spending two years in another unit.

A substantial number of the scheme's 20 senior registrars have an interest in psychotherapy. Preference is given to trainees who have not been at Uffculme as registrars and to those who express a wish to train for a consultant post in which they will have opportunities for a special interest in psychotherapy. As such consultant posts are limited, most senior registrars keep their higher psychiatric training broadly based lest they should restrict future job opportunities.

Senior registrars unable or unwilling to attend Uffculme full-time are encouraged to take part in a two-year multidisciplinary course in psychotherapy. This takes half a day a week. The first year includes seminars on basic psychotherapeutic concepts and techniques, and a sensitivity training group. The second year involves a more intensive personal group experience. A personal analytic experience is not regarded as essential, but trainees who see this as impor- 